\title{
Current Emotion Research in the Language Sciences
}

\author{
Asifa Majid \\ Max Planck Institute for Psycholinguistics, The Netherlands \\ Donders Institute for Brain, Cognition, and Behavior, Radboud University, The Netherlands
}

\begin{abstract}
When researchers think about the interaction between language and emotion, they typically focus on descriptive emotion words. This review demonstrates that emotion can interact with language at many levels of structure, from the sound patterns of a language to its lexicon and grammar, and beyond to how it appears in conversation and discourse. Findings are considered from diverse subfields across the language sciences, including cognitive linguistics, psycholinguistics, linguistic anthropology, and conversation analysis. Taken together, it is clear that emotional expression is finely tuned to language-specific structures. Future emotion research can better exploit cross-linguistic variation to unravel possible universal principles operating between language and emotion.
\end{abstract}

Keywords

categorization, emotion, language sciences, linguistics, sound-symbolism

According to a long-standing and dominant view, language is the product of an innate, universal, domain-specific and encapsulated module (Chomsky, 1980; Fodor, 1983; Pinker, 1994). In recent years, there has been a shift away from this perspective and researchers are questioning many of these fundamental assumptions (Christiansen \& Chater, 2008; Hagoort \& Van Berkum, 2007; Langacker, 1987). Increasingly, linguists are engaging with ideas from evolutionary biology to think about language evolution and language change (e.g., Dunn, Greenhill, Levinson, \& Gray, 2011). This brings to the fore linguistic diversity, highlighted in a recent article by Evans and Levinson (2009). The idea of a single underlying linguistic system different only in surface realization seems increasingly unlikely.

If languages are so different from one another then we need to understand how and why. This gives prominence to sociolinguistics and linguistic anthropology. At the same time, there is ever more interaction between linguistics and psychology, in particular through the subfield of psycholinguistics. As a result, this article presents highlights of emotion research from the language sciences broadly defined, including, where relevant, insights and findings from these ancillary fields.

There are a number of questions regarding the interaction between emotion and language, each of which could be asked at different levels of structure, as suggested by Wilce (2009, p. 3), who reasons: "nearly every dimension of every language at least potentially encodes emotion." Language is at the nexus of cognition, on the one hand, and culture on the other. It is private, so intertwined with thought so as to seem inseparable; yet it is also public, being the medium of communication. Language, then, is the ideal forum to examine the relationship between culture and cognition: How is emotion expressed in language? How do cultural forces shape the language of emotion? Does language in return impact on cognition and culture? These central questions are not answered in these pages, but I pose them to illustrate the critical role of language in emotion research.

It is perhaps helpful to unpack further the notion of meaning so as to better understand how emotion might be encoded in language. Linguistic meaning is complex and multifold. There is the referential or descriptive aspect of meaning (things in the world denoted by a linguistic word or form) and the concomitant intension (the relationships between forms, such as taxonymy, synonym, etc.). Forms carry connotative meaning, where emotion is not entailed but implied. Expressive meaning conveys the speaker's feeling or attitude towards the content of the message, while social meaning indicates something about the speaker's social role and stance (cf. Cruse, 1986; Lyons, 1977). 
These distinctions map (loosely) to the distinctions made within psychology between emotion, affect, and attitude (Barrett \& Bliss-Moreau, 2009; McGuire, 1969; Russell, 1980). The descriptive meaning of emotion words is taken to refer to discrete states, such as "happiness," "anger," and "sadness." Connotative meaning maps to the general dimensions of arousal and valence. Expressive meaning captures speakers' attitudes or evaluations about a proposition. Linguists typically focus on one of these aspects to the exclusion of others: Cognitive linguists, for example, almost exclusively study reference and discrete emotions, while linguistic anthropologists focus on social meaning and use "affect" as a coverall term (Besnier, 1990; Kulick \& Schieffelin, 2004). Here, "emotion” is used as the superordinate term to cover the aforementioned distinctions (cf. Wilce, 2009).

This review outlines aspects of linguistic structure where emotion might reveal itself. More attention is devoted to aspects of "emotion and language" where previous reviews have been silent. I only briefly touch on prosody and lexicon. Both these areas have been reviewed previously, so I do not dwell on them. More space is devoted, instead, to topics such as sound-symbolism and related phenomena (e.g., interjections, ideophones), which hitherto have been marginalized. As the modular view of language dwindles, many in the language sciences have shifted from viewing meaning as amodal and propositional to increasingly "embodied," and so these topics have become ever more prominent. I also highlight some aspects of grammar that are little considered in the context of emotion and language. Finally, some recent studies of emotion in the context of discourse, both in narrative and conversation, are discussed.

\section{Sounds}

I cannot doubt that language owes its origin to the imitation and modification, aided by signs and gestures, of various natural sounds, the voices of other animals, and man's own distinctive cries [. . .] we may conclude from a widely spread analogy that this power would have been especially exerted during the courtship of the sexes, serving to express various emotions, as love, jealousy, triumph, and serving as a challenge to their rivals. The imitation by articulate sounds of musical cries might have given rise to words expressive of various complex emotions. (Darwin, 1871, p. 56)

Darwin in this quote points to the close relationship between emotion and sound in evolutionary terms, a sentiment echoed by scholars over the years (cf. Christiansen \& Kirby, 2003). Regardless of whether emotional expression was the original impetus for language evolution or not, we can nevertheless ask of the 6,000 or so languages spoken today: Is there evidence for a continuing tight link between speech sounds and emotions? To answer this question it is important to distinguish different aspects of speech sounds. There are the physical parameters related to a sound's acoustic properties: how sound is produced physiologically and how it is perceived auditorily. Sounds vary in loudness, pitch, duration, length, voice quality, and so forth. In addition, there are those sounds - consonants and vowelsthat combine to make meaningful units, such as words, within a language. For any one of these speech sound parameters we could ask whether they are used to signal emotion.

\section{Prosody}

Prosody refers to the "structure that organizes sound"; that is, qualities of speech including pitch, tempo, loudness, and so on (Cutler, Dahan, \& Van Donselaar, 1997, p. 142). Speakers raise their voices, speak at a higher pitch, and lengthen vowels to signal a particular emotion or emotional intensity (Goodwin \& Goodwin, 2001; Jespersen, 1922; Wilce, 2009). Voice qualities, like harsh, tense, breathy, or whispery, can likewise indicate emotional state (Gobl \& Ní Chasaide, 2003). In Zapotec, a language spoken in Mexico, speakers use different phonation types to mark different speech registers: Speaking with a high pitch falsetto indicates respect; using a breathy voice demonstrates authority; while a creaky voice seeks commiseration (Sicoli, 2010). Here, sound features index social roles. Although it has been suggested that speaking louder, at higher pitch, and so forth, heralds greater depth of feeling, in everyday conversation there are complex cues and dynamics at play, making it unlikely that loudness, for example, always signals greater intensity (Barth-Weingarten, Reber, \& Selting, 2010).

Experimental evidence suggests that speakers can recognize discrete emotions from paralinguistic features across spoken languages (e.g., Pell, Monetta, Paulmann, \& Kotz, 2009; Pell, Paulmann, Dara, Alasseri, \& Kotz, 2009; Scherer, Banse, \& Wallbott, 2001; Thompson \& Balkwill, 2006) as well as sign languages (Hietanen, Leppänen, \& Lehtonen, 2004; Reilly, Mcintire, \& Seago, 1992). For example, Pell, Monetta, Paulmann, \& Kotz (2009) played Spanish, English, German, and Arabic recordings of "pseudo-utterances" (i.e., utterances without semantic content) to Spanish participants who had to decide which emotion was being expressed: anger, disgust, fear, sadness, joy, or neutral. Recognition rates by Spanish speakers were significantly above chance for all four languages. This study, and the others cited earlier, are suggestive of crosscultural recognition of specific emotions; but many of these articles compare languages that are closely related (typically Indo-European languages) or share other linguistic characteristics (for example, English and Chinese both have subject verb object [SVO] word order and are morphologically more analytic; Comrie, 1981). These shared characteristics urge caution in the face of claims such as "vocal expressions of the emotions investigated [. . . contain invariant or 'modal' elements which are universally exploited by speakers and can be decoded across languages irrespective of the linguistic ability and experience of the listener" (Pell, Monetta, Paulmann, \& Kotz, 2009, p. 116).

It is important to consider the relevant cross-linguistic facts. The "same" paralinguistic features can play different roles across languages. Take pitch, for example: In English pitch is implicated in word stress and thus can help disambiguate nouns from verbs (e.g., PERmit vs. perMIT), while lexical-tone languages use pitch to distinguish between words. Indeed, when expressing emotion, pitch is less important in Chinese, a lexical tone language, and instead speech rate is more relevant (Anolli, 
Wang, Mantovani, \& De Toni, 2008). Pitch can also signal phrase boundaries, yes-no questions, and other pragmatic information. So, a child or second-language learner must learn to parcel out language-specific functions of pitch in order to tune into the emotion-relevant ones. This takes time to figure out (Friend, 2000; Quam \& Swingley, 2012).

One other pertinent detail relating to the aforementioned studies on emotion and prosody is that they typically use enacted or posed materials. Future research will have to bridge the gap between how speakers display emotions in everyday conversation and how they simulate them when told to produce them on demand in experimental settings. Finally, it is regrettable that many studies in this area do not report the language background of their participants; bilingualism is potentially a serious issue for interpreting results. For reviews of recent literature on emotion and prosody, see Russell, Bachorowski, and FernándezDols (2003) and Scherer, Clark-Polner, and Mortillaro (2011).

\section{Phonetics and Phonology}

What about phonemes, the vowels and consonants of a language? Do these reliably signal specific emotions? Most linguists would answer no. The arbitrary relationship between the sound of a word and its meaning is taken to be a defining feature of language. Human languages exhibit "duality of patterning": meaningless sounds are combined to make meaningful words (Hockett, 1960).

For any language, we can identify those speech sounds which constitute its phonological inventory; that is, minimal sounds that distinguish between words. For example, $/ \mathrm{p} /$ and $/ \mathrm{b} /$ are two phonemes in English which distinguish the words pin and bin. Establishing a language's phonology is not as straightforward as it initially appears since speakers realize the same speech sound in different ways. For example, in most varieties of English the sound /t/ is pronounced differently when it is at the beginning of a word (e.g., top) than when it is in the middle of word (e.g., butter), but they are nevertheless the same from the perspective of a native English speaker. In top, $t$ is pronounced with a slight burst of air [ $\left.\mathrm{t}^{\mathrm{t}}\right]$ (whereas in stop it isn't). In my native dialect, the $t$ in butter is pronounced with a glottal stop [?], produced by transiently stopping airflow in the vocal tract. These pronunciation variants are all allophones of $/ t /$, but in another language they could be distinct phonemes in their own right (as they are, for example, in Hindi). By following a series of comparisons, a linguist can identify the total set of phonemes within a language.

Across the world, the inventory size of phonemes varies considerably: Rotokas (spoken in Papua New Guinea) has only six consonants, whereas !Xóõ (spoken in Botswana), at the other extreme, is reported to have 122 consonants. Like other Khoisan languages, !Xóõ utilizes contrasting click sounds as part of its phonological inventory. On average, languages have a modest inventory of around 20 consonants (Maddieson, 2011a; see also Robinson, 2006). Vowels show a smaller range of variation. The smallest number of vowels in a language is two (the language
Yimas of Papua New Guinea), the largest 14 (German), with an average of six across languages (Maddieson, 2011b).

This variation speaks to the essential arbitrariness of soundmeaning associations, suggesting it is implausible that specific sounds are associated with specific emotional meaning. However, there are those that do argue for a tighter link between sounds and emotions than this standard view holds. The linguist Jespersen, for example, argued:

If grumble comes to mean the expression of a mental state of dissatisfaction, the connection between the sound of the word and its sense is even more direct, for the verb is imitative of the sound produced by such moods, cf. mumble and grunt, gruntle. The name of Mrs. Grundy is not badly chosen as a representative of narrow-minded conventional morality. A long list might be given of symbolic expressions for dislike, disgust or scorn. (1922, p. 26, italics in original)

Within literary studies many have likewise noted correspondences between sounds and emotion. Fónagy (1961), for example, compared aggressive and tender poems by the Hungarian poet Petöfi and found that $/ \mathrm{t} /, / \mathrm{k} /$, and $/ \mathrm{r} /$ were more frequent in aggressive poems, while $/ 1 /, / \mathrm{m} /$, and $/ \mathrm{n} /$ were more frequent in tender poems. Masson (1953), when considering various European poets, argued that $/ \mathrm{o} /, / 1 /, / \mathrm{m} /$, and $/ \mathrm{w} /$ suggest liquidity, softness, and coolness. Likewise, Tsur (1992) suggests /1/ is liquid, periodic, and soothing. In the last decade or more, there have been attempts to test these posited associations statistically. For example, Whissell (1999) transcribed poetry, song lyrics, advertisements, and various types of popular fiction into a phonemic transcript and then tested whether certain categories of phonemes appear more often in particular genres. Independently, she calculated the emotional tone of each text by averaging the pleasantness and activation scores of words that also appear in the "Dictionary of Affect in Language" (see Whissell, 1989). Using this procedure, Whissell found a number of associations between categories of phonemes (e.g., bilabial consonants, $/ \mathrm{m} /$, $/ \mathrm{p} /, / \mathrm{b} /$ ) and emotion (e.g., aggressiveness), through the higher than chance appearance of those phonemes in certain genres (e.g., Zeppelin lyrics, boy's advertisements). Using a similar approach, Whissell (2003) found that texts with more /i/ phonemes tend to be more pleasant, while those with /I/ phonemes were more active.

More recently, Auracher, Albers, Zhai, Gareeva, and Stavniychuk (2010) tested the cross-cultural validity of these emotional sound-symbolic associations. Auracher et al. selected a number of poems from German, Russian, Ukranian, and Chinese and calculated the ratio of plosives (e.g., /p/) to nasals (e.g., $/ \mathrm{n} /$ ) in each poem. They then selected the poem with the highest and lowest ratios in each language and asked native speakers to rate those poems on a number of parameters, including happiness, arousal, aggression, and melancholy. Across languages, they found an association between consonants and emotionality which they state "clearly suggests there is a universal tendency to express happy and active feelings with plosive sounds, whereas sad and passive feelings are encoded in nasal sounds" (Auracher et al., 2010, p. 21). 
In an independent line of inquiry, Zajonc and colleagues (McIntosh, Zajonc, Vig, \& Emerick, 1997; Zajonc, Murphy, \& Inglehart, 1989) argue that facial feedback whilst producing vowels causes distinct emotion states. They focus, in particular, on the German vowel ü, /y/, which they claim "constricts the nostrils, and pushes the mouth and brows forward, as in a scowl" (McIntosh et al., 1997, p. 177). In a number of studies, Zajonc and colleagues tested Americans and Germans for pleasantness and mood after uttering the vowel itself or when embedded multiple times within a story. In line with their prediction, they found that participants had lower pleasantness and mood ratings when they produced ü than any other vowel. Overall, these studies point to the same conclusion: There are robust sound-emotion correspondences, which are likely universal.

There are, however, a number of problematic points that hold across these studies. In general, when texts are compared for associations between sounds and emotions they differ on a number of parameters, aside from the test phoneme, including length, rhyme, frequency of non-critical phonemes, and so forth. These confounding elements make it difficult to interpret the results unambiguously. In addition, the studies do not take into consideration the fact that words do not appear independently of each other; rather, when discussing a certain topic, keywords are likely to reappear, thus inflating calculations of the relative frequency of letters/phonemes and their likely association with emotions. Where statistical tests have been conducted, they are numerous with no correction for multiple comparisons.

Zajonc et al.'s studies are exemplary in experimental control, but the underlying premise of these studies is highly dubious. It is claimed that the same muscles involved in the production of $/ \mathrm{y} /$, such as the corrugator muscle, are also implicated in negative emotions. However, the only reason articulation of $/ y /$ would involve frowning is if participants found it difficult to produce, which is quite plausible since the participants in these studies were either English monolinguals or English-German bilinguals. English does not have a phoneme /y/ and English speakers find it notoriously hard to produce. For native monolingual Germans, $/ y /$ does not involve the corrugator muscle, nor does it entail constriction of the nostrils (Von Essen, 1979). There has been no test of the greater negativity of ü with native monolingual speakers of German, so we do not know whether the posited sound-emotion association exists.

To date, the most convincing study of a possible universal association between sounds and emotions has been conducted by Taylor and Taylor (1965). They constructed nonsense words in four unrelated languages-English, Japanese, Korean, and Tamil — using sounds that were common (as far as possible) to all languages. Monolingual participants then judged the words for pleasantness. The main result of this study was that soundemotion associations were language-specific: Within a language community people were consistent in their pleasantness ratings of sounds, but pleasant sounds were different across languages (see also Iwasaki, Vinson, \& Vigliocco, 2007a, 2007b).

Other evidence also hints at language-specific soundmeaning pairings. In English, words beginning with $g l$-, such as glitter, glow, gleam, glisten, and so on, all relate to "vision" and "light"; words beginning with sn-, snore, snarl, snort, sniff, and so on, relate to "nose" and "mouth," and speakers are sensitive to this relationship (Bergen, 2004). Frequent English verbs are more likely to have front vowels, whereas frequent nouns are more likely to have back vowels; speakers categorize words faster as nouns or verbs if they obey this regularity (Sereno, 1994). There may be such regularities in emotion words too: Sneer, leer, jeer, for example, all share the final -eer, and Bergen (2004) proposes -eer means "expression of contempt." Future studies will determine whether speakers are sensitive to these sorts of language-specific sound-emotion regularities.

\section{Words}

When thinking about "language and emotion," the lexicon is most salient; that is, words denoting or referring to emotions, for example angry, happy, and sad. Considerable work has focused on emotion lexicons, most notably by Wierzbicka and her colleagues (Enfield \& Wierzbicka, 2002; Harkins \& Wierzbicka, 2001; Wierzbicka, 1996, 1999). Both micro-level studies, focusing on specific words (see Ogarkova, in press, for further references), and macro-level comparisons of whole lexicons (e.g., Alonso-Arbiol et al., 2006; Moore, Romney, Hsia, \& Rusch, 1999; Toivonen et al., 2012) have been conducted in several languages, using a variety of methods (see Boster, 2005, for a critical review). Where differences have emerged, researchers have asked what the concomitant differences in non-linguistic cognition might be (Breugelmans \& Poortinga, 2006; Sauter, LeGuen, \& Haun, 2011; see also Roberson, Damjanovic, \& Kikutani, 2010). These studies are not discussed further; instead I focus on emerging trends in emotion lexicon research.

\section{Interjections}

Interjections are little words expressing emotional or mental states that can stand alone as an utterance and, under usual circumstances, do not combine to form a construction with other word classes (Ameka, 1992). Examples are Wow!, Ah!, Oh!, Gee!, and Oops! According to Goffman (1981, p. 99), "We see such 'expression' as a natural overflowing, a flooding up of previously contained feeling, a bursting of normal restraints, a case of being caught off guard," or, rather, "[t]hat is what would be learned by asking the man in the street if he uses these forms and, if so, what he means by them."

In a novel study, Sauter, Eisner, Ekman, and Scott (2010) tested whether speakers of Himba, a small-scale speech community resident in Namibia, could recognize vocal expressions of emotion from speakers of English, resident in the United Kingdom, and vice versa. Sauter et al. presented participants with short stories and then asked them to indicate which of two vocalizations best fit the story. They found speakers were able to assign appropriate vocalizations to stories, even when they came from the non-familiar language. Although the speech sounds were characterized by the authors as "nonverbal," many could be classified as interjections. In the past, 
linguists also considered interjections as direct outpourings of emotion or on the fringes of language (e.g., Jakobson, 1960), but today they are widely accepted as clearly linguistic tokens (Kockelman, 2003). Interjections vary cross-culturally in form (Wierzbicka, 1992). Jespersen (1922, p. 415) makes a charming reference to a Kipling story in this regard: "That man is no Afghan, for they weep 'Ai! Ai!' Nor is he of Hindustan, for they weep 'Oh! Ho!' He weeps after the fashion of the white men, who say, 'Ow! Ow!'.”

Within a language, interjections tend to be phonologically anomalous, often containing sounds and sound sequences not found in other parts of the lexicon. They are morphologically unusual: They do not partake of inflections or derivations applicable to other word classes; on occasion they do display morphology; they do not obey agreement rules, and so on. Their semantics have also been argued to vary considerably across languages (Wierzbicka, 1992; Wilkins, 1992). They are likely to be a word class in all languages of the world (Ameka, 1992).

In this context, Sauter et al.'s study raises a number of interesting questions. The fact that Himba and English speakers were able to correctly categorize interjections from each others' languages suggests that some aspect of emotional meaning is interpretable cross-culturally. This is potentially at odds with the attested variation in meaning suggested elsewhere. Wierzbicka (1992), for example, notes that Greek feu is an interjection of grief and anger, while the almost identical English phew signals relief. It is unclear, however, whether Sauter et al.'s findings are due to participants recognizing the phonological forms (as a result of "universal" sound-symbolism, perhaps) or whether participants were responding to the paralinguistic cues (i.e., prosody). Speakers can clearly read different emotional meanings from the same interjection, depending on prosody. Couper-Kuhlen (2011) shows, for example, that the "surprise" token oh, produced with low volume, low pitch, breathy intonation, and weak articulation, can indicate disappointment, whereas when produced at a high pitch, with high volume and sharp voice quality, it can signal anger. Nevertheless, it could be argued that, in both cases, oh also expresses that something unexpected occurred. So, future work will need to distinguish between these different channels of expression.

As stated earlier, interjections have been said to occur in all languages, but it is not known whether the types are also the same across languages and, if so, what internal states they express, if any (cf. Kockelman, 2003; Wharton, 2003). Interjections also bring out a number of thorny issues in linguistic theory: If interjections are stored in the lexicon, then how do we account for their unusual phonology? How are verbless, nounless utterances handled by grammar? What is the distribution of labor between semantics and pragmatics? This word class is ripe for further investigation.

\section{Ideophones}

Ideophones, like interjections, are an unusual class of words. Dingemanse (2011) characterizes them as "marked words that depict sensory imagery": they are unusual in their sound patterns, morphology, and grammatical behavior and seem to be designed precisely so as to express inner experience. Take gbadara-gbadara, an ideophone from the language Siwu, spoken in eastern Ghana. Dingemanse suggests that, while its paraphrase "walking unevenly and out of balance" merely describes a gait, gbadara-gbadara depicts it by vividly conjuring a sensory image to mind. This depictive property sets ideophones apart from interjections. Whereas interjections are tied to the here-and-now and are immediate responses to perceptions (e.g., ouch said on touching something hot), ideophones, instead, can be used at any time to depict and describe (Dingemanse, 2011).

Ideophones - sometimes also called expressives or mimetics - are commonly found in far-flung, unrelated languages across the globe; Indo-European languages seem aberrant for missing this word class (Diffloth, 1972; Nuckolls, 1999). The fact that they are found in the majority of the world's languages calls for exegesis.

The precise semantic domains expressed by ideophones vary between languages, be it size, texture, movement, color, and so on. Japanese ideophones seem particularly rich in expressing inner states. Oda (2000) provides some examples: doki doki 'excited,' hiya hiya 'being nervously fearful of (the outcome), noro noro 'sluggish,' odo odo 'being shy and timid,' and so on. His collection includes 1,600 ideophones, which is apparently only scratching the surface (Imai, Kita, Nagumo, \& Okada, 2008).

Osaka and Osaka (2005) have found that Japanese speakers listening to laughter ideophones, such as ghera-ghera, kusukusu, and nitah-nitah, show greater activation of striatal reward centers than when listening to non-words, suggesting the same neural circuits involved in experiencing humor are recruited in understanding the meaning of laughter words. Japanese mothers use ideophones frequently in child-directed speech, and they appear to be of special value in language learning (Imai et al., 2008; Iwasaki et al., 2007a, 2007b). It is unknown, however, whether ideophones elicit greater "imagery" or "resonance" than other word classes with similar meanings. What is clear, in any case, is that ideophones ought to be of special interest to emotion researchers. In some languages the main function of ideophones is to depict emotion; when their core meaning lies elsewhere, they nevertheless have strong emotional connotation; and they play a special role in creating emotional alignment between speaker and hearer.

\section{Metaphor}

As the previous sections illustrate, emotion lexicons are incredibly rich across languages. Words and phrases do not exist as isolated entities, however, but form interconnected networks. One such supra-lexical structure is metaphor. A burgeoning literature within cognitive linguistics explores emotion metaphors, such as ANGER IS HEAT (e.g., Kövecses, 2003; Lakoff, 1987). These analyses have led to the provocative proposal that linguistic metaphors are cognitively real. Indeed, English speakers presented with anger-related words judge temperatures as higher (Wilkowski, Meier, Robinson, Carter, \& 
Feltman, 2009) and "see" red (Fetterman, Robinson, Gordon, \& Elliot, 2011), consistent with their language metaphors.

Metaphors such as ANGER IS HEAT have been presumed to be grounded in universal perception and physiology. However, Geeraerts (2006) argues that these metaphors are the result of historical cultural schema. He claims that the ancient humoral theory of medicine permeates contemporary lexicons of English and related languages, as exemplified by words like bilious 'angry, irascible, hot-tempered' and zwartgalling 'sad, depressed (literally black-bilious)' in Dutch. Imbalance of the humors can explain a number of pervasive emotion metaphors, according to his analysis. Moreover, the humoral account of metaphor would predict why physiological effects parallel to anger when accompanying other emotions, such as shame (i.e., faceflushing, the subjective experience of increased temperature), do not lead to parallel metaphorical expressions. That is, we do not have expressions in English like his blood boiled with shame or she was fuming with shame (although, contra to Geeraerts' claims, English does have expressions such as her face burnt with shame). This account requires further diachronic linguistic work. Some historical analysis shows that emotion terms frequently arise from concrete verbs: worry, originally meaning 'strangle, seize by the throat,' preoccupy 'seize beforehand,' stun 'deprive of consciousness with a blow,' fascinate 'cast a spell over,' and so on (Haspelmath, 2001, p. 79). However, whether these changes can be motivated by cultural schema is unknown.

Geeraert's analysis also raises the question of the variability of metaphors across cultures. Although assertions of universality are commonly found in the metaphor literature, the data on which these claims are based are rather slim: a few observations from a handful of WEIRD communities (Henrich, Heine, \& Norenzayan, 2010), while neglecting $95 \%$ of humanity (Arnett, 2008). Current studies focus almost exclusively on European languages, with known contact and common descent, and a few other major world languages, such as Chinese and Japanese. But there are known confounds in sampling only large languages (e.g., Lupyan \& Dale, 2010; Trudgill, 2011). In one study of a small endangered language, we find that speakers of Tsou (around 4,500 people living in the highlands of Taiwan) rarely make use of emotion metaphors. Metaphors such as FEAR IS A NATURAL FORCE (e.g., she was engulfed by panic) and FEAR IS A FLUID IN A CONTAINER (e.g., the sight filled him with fear) simply do not exist in the language (Huang, 2002). More such careful and detailed case studies are essential.

Finally, in other domains where cross-linguistic variation in metaphor has been attested, for example, in vocabulary for sounds (e.g., Eitan \& Timmers, 2010; Shayan, Ozturk, \& Sicoli, 2011), we find accompanying variation in non-linguistic conceptualizations (Dolscheid, Shayan, Majid, \& Casasanto, 2011). Whether the same holds for emotion remains to be seen in coming years.

\section{Other Aspects of the Lexicon}

If a language has a sizeable adjective class - which not all languages do - then emotions will feature there, along with perceptions, appraisals, and so forth (Dixon, 2006). But, of course, emotions can be expressed in many different ways. For example, in Totonac, spoken in Mexico, emotion roots are verbs, which are turned into nouns by a morphological process and augmented with the instrumental applicative $l i:-$, resulting in a meaning of 'that causes the emotion expressed by V;' for example, the intransitive verb ma:xanán ' $\mathrm{s} / \mathrm{he}$ is ashamed' becomes li:ma:caná 'that causes shame, shameful' (see contributions in Dixon \& Aikhenvald, 2006, for examples of how other languages code emotions).

In English, "fear" can be a noun (a terrible fear struck his heart), adjective (he was afraid), adverb (John was fearful for his life) or verb (John feared Mary). Even within the same word class different forms can be chosen. Compare John fears Mary versus John frightens Mary. These different verbs carry different implications. When asked who is the cause of the event, causation is attributed to John in John frightens Mary but to Mary in John fears Mary (Brown \& Fish, 1983). Participants look for causes when reading John respects Mary (where respect functions as a verb), but consequences after reading about the identical scenario but now presented in a ditransitive construction, John gave respect to Mary (where respect now functions as a noun; Majid, Sanford, \& Pickering, 2007).

Choice of verb can impact judgments of how long an event lasts, how much information can be inferred about the subject and the situation, whether the event is deemed verifiable or disputable, and so on (Semin \& Fiedler, 1988). Verbs of emotional expression (e.g., to smile, to frown) elicit more activation of the corresponding facial muscles than do adjectives associated with those expressions (e.g., funny, annoying), even when verbs and adjectives are matched for valence (Foroni \& Semin, 2009). These examples serve to illustrate the myriad ways in which emotion terms are lexicalized, each with their own subtle consequences for conceptualization and thinking.

It is unknown at present whether these within-language effects are mirrored across languages; that is, do languages which differ systematically in whether they encode emotions as adjectives, nouns, or verbs show correspondingly different habitual patterns of thinking? Wierzbicka (2009) suggests that English speakers, who use adjectives more frequently to code emotions, conceptualize emotions as states but Russian speakers, who use verbs, conceptualize them as activities instead. Huang (2002) makes a different kind of prediction. He proposes that Tsou lacks emotion metaphors because emotions are expressed as verbs in the language. According to him, coding emotions as nouns reifies them and makes them objects, which is not the case if a language codes them as verbs. The reification promotes metaphorical mappings, making them more abundant. These ideas could easily be tested in future cross-linguistic research.

\section{Grammar}

Individual words behave in certain ways according to the grammar of the language. For example, kiss in English can take the plural morpheme $-(e) s$ when it functions as a noun (e.g., 
Mark gave Sarah three kisses), but combines with different morphemes, such as the past -ed, when it functions as a verb (e.g., Mark kissed Sarah). Morphemes are the smallest meaningful units in a language and can be either free, like kiss, or bound, like $-(e) s$ and $-e d$, where they can only occur in conjunction with other morphemes. In the next section I present two case studies of emotion in morphology. Beyond the morpheme, there are principles structuring how words combine to form sentences. The section on Syntax describes some of the special machinery involved in handling emotion.

\section{Morphology}

Many languages have bound morphemes, or affixes, which literally mean "small" but which additionally convey a range of meanings, including sympathy, endearment, intimacy, playfulness, and so forth. In general, diminutives mark positive evaluation of the object to which the form refers. Augmentatives, the opposite of diminutives, convey instead emotional distance or negative stance (Silverstein, 2001). A recent study on the acquisition of diminutives by Spanish-speaking children in Peru suggests that these pragmatic meanings may not be acquired until relatively late (King \& Melzi, 2004), but the precise developmental trajectories for acquiring the various meanings of diminutives and augmentatives are not known.

In Lakhota, a Siouan Language of North America, there is a set of clitics which have been characterized as indicating both the gender of the speaker and specific speech acts. So, for example, a woman's opinion is stereotypically marked with the clitic $l e$ and a man's with $l o$; a woman marks something as surprising by using $m q$, while a man uses $w q$, and so forth (Trechter, 1999). Clitics can be flexibly juxtaposed to create certain effects. For example, Trechter describes an older man arriving home to find his 3-year-old nephew playing on his stoop. He exclaims his surprise and pleasure by declaring: Walewa hiyu wele "Oh m., look who's come $\mathrm{f}$." In this utterance, the surprise particle at the beginning is marked as masculine, but the clitic at the end is marked feminine. Trechter argues that, because women are deemed more experienced dealing with children, women's register is considered nurturing and affectionate. By using the feminine-marked clitic, the man is implying that he himself is nurturing.

Surprise is often coded grammatically across the world's languages. Known as the "mirative" in linguistics, this category expresses that something is unexpected to the speaker. It is expressed morphologically in some languages - as in Lakhotawhile in others it appears as a grammaticalized construction (Delancey, 1997). Other "basic" emotions, such as fear, disgust, or anger, appear not to receive this sort of treatment in grammar.

\section{Syntax}

As indicated earlier in the section on metaphor, emotion verbs often start out with concrete meanings and gradually come to acquire emotion meanings. When these verbs have concrete meanings they behave like normal transitive verbs. But as they lose their original concrete meanings these verbs also change their grammatical behavior, leading to a different type of marking of the grammatical subject (Haspelmath, 2001). Verbs of emotion, along with those of perception and cognition (called psych-verbs or psych-predicates in the linguistics literature), stand out in their grammatical encoding. Although emotion receives special treatment, it often does not get singled out as distinct from other sorts of subjective states, such as desiring, wanting, cognizing, and so forth. This conflation between emotion and other internal states has been noted frequently in discussions about the lexicon, but is less noted with regards to their grammatical treatment (although see Wierzbicka, 1988).

In standard average European languages the prevalent and "canonical" way to describe emotions is to use an agent-like experiencer construction where the verb is treated like a typical transitive predicate; that is, the experiencer is marked as a subject and the stimulus is marked as if it were an object; for example, John hates cats. Other constructions carry different implications and suggest different construals of emotion. In the dative-experiencer construction the experiencer is marked with dative case and the stimulus now functions like a subject, for example, French Ce livre lui plait, 'This book is pleasing to him.' A third type of construction, the patient-like construction, treats the experiencer as an object and the stimulus as a subject, for example, This problem worries me (Haspelmath, 2001).

Choice of construction can change the interpretation of a sentence from physical state to subjective state instead, as illustrated in this Icelandic example: Mig kelur (first person + singular + accusative is freezing) 'I am freezing/getting frostbitten,' with accusative marking, is interpreted as referring to the physiological state of coldness, while Mer kolnar (first person + singular + dative is getting cold) 'I am getting cold,' with dative marking, is interpreted as referring to the psychological experience (cited in Onishi, 2001). In South Asian languages, like Bangla (spoken in Bangladesh), feelings are encoded as the grammatical subject in impersonal constructions, with the verb lag- 'strike.' The experiencer is often left implicit; if it is expressed at all it takes dative case, for example terror strikes (me) (Klaiman, 1980; Wilce, 2009). It has been suggested when this construction is used that the experiencer is being construed as a location (Landau, 2009), the person is merely the recipient of the emotion, that is that the emotion comes to them (e.g., Lindholm, 1975), and that the emotion is less volitional (Klaiman, 1980). This raises the linguistic relativity question once again: Do speakers of languages like Bangla conceptualize emotions as moving towards them or as being less under their control? No one has tested these predictions independently of language.

Japanese has an intriguing restriction in how emotional states can be talked about: Only one's own psychological states can be reported directly. That is, feelings, desires, mental activities, and so on, can be expressed with a first-person subject (i.e., I), but not with second- or third-person subjects (e.g., you or John). Here, the grammar-lexicon interface reflects that 
while I can have direct access to my own subjective feelings, I cannot have direct access to anyone else's emotions or thoughts. So, while it is perfectly acceptable to say Watashi wa kanashi-i 'I am sad,' it is not acceptable to say Haha was kanashi-i 'My mother is sad.' This second sentence can only be interpreted to mean that the mother is the source of the feeling, that is 'My mother makes me sad.' To talk about another's subjective states, you have to be explicit about the indirect nature of your information, by using terms such as -garu 'shows signs of,' rasii 'seems,' soo da 'looks as if,' or otherwise indicating that the information is not directly accessible (Hasegawa \& Hirose, 2005; Shibatani, 1990).

Body parts, usually internal organs, are often thought to be the seat of emotions (Enfield \& Wierzbicka, 2002; Yu, 2003). In Yélî Dnye, a language spoken on Rossel Island in Papua New Guinea, the seat of emotion is the throat/neck. Variation in case marking differentially indicates positive versus negative emotions. The locative form of the word for throat, nódo 'at the throat,' collocates with both positive and negative affect expressions, while the absolutive form, nuu 'throat,' collocates with expressions of positive affect. Compare Yi kópu a nódo ka $t: a$ 'I feel bitter about it' (literally, 'That thing is hanging at my neck') to A пии u tpile 'A thing I really like' (literally, 'My throat its thing;' Levinson, 2006).

Le Guen (2009) notes that specific emotions can receive distinct grammatical treatment. In Yucatec Maya, for example, 'to love (someone)' has different grammatical coding from 'to like;' the former is used in a passive construction without aspect, but with a change in transitivity. Little is known about the extent to which discrete emotions receive differential grammatical coding across languages.

Affect-laden terms, such as damn, bloody, and fuck, are also interesting with respect to their grammatical behavior. For one thing, they challenge classical theories of meaning since they do not alter the truth-conditional meaning of the phrase to which they attach. In the sentence The handlers stole my pink iPod, the sentence is true if, and only if, the baggage handlers stole my pink iPod, but would be false if they stole my blue iPod instead. But in The handlers stole my damn iPod, damn does not modify iPod; the sentence is true if the baggage handlers steal an iPod of mine, whatever its characteristics. Rather than modifying iPod, damn conveys the speaker's attitude of vexation (Potts et al., 2009; Pullum \& Rawlins, 2007). It is also not clear how to characterize the syntax of affect-laden expressions, like Fuck you. Perhaps Fuck you is just a second-person imperative like Close the door: both lack an overt grammatical subject. However, various grammatical tests show this is not the case. Imperatives, like Close the door, can be embedded in a number of other constructions: I said to close the door; Don't close the door; Go close the door, and so on. But Fuck you cannot: *I said to fuck you; *Don't fuck you; *Go fuck you, and so forth (Zwicky, Salus, Binnick, \& Vanek, 1971; see also Pinker, 2007).

This section does not even begin to do justice to the richness of grammatical encoding of emotions and other internal states.
For a recent overview of related phenomena from a crosslinguistic perspective see Verhoeven (2007, Chapter 3).

\section{Discourse}

At the beginning of this article, I raised the issue of sound symbolism for emotions in the context of isolated sounds. Arguably, it is not a single sound that gives rise to an emotional effect, but rather a sound in the context of a stretch of discourse. As Miall (2001, p. 69) states, "the specific qualities that emerge from the array of phonemes in a text depend on the contrasts offered by the text." Through sound-play, metaphor, and repetition, a literary author can invoke a certain emotional impact on the reader. This highlights the fact that emotion can be inferred from larger stretches of narrative. In this section, some aspects of emotion in the context of narrative comprehension and during conversation are considered.

\section{Discourse Comprehension}

Understanding the emotional significance of events in narrative is crucial for understanding characters and motivations, and can help explain key plot moments (Oatley, 1992). There can be references to emotion in conversations of characters, portrayals of facial expressions and movements, and descriptions of actions resulting from an emotional episode. In written texts we can get into the minds of characters, allowing us to overhear thought processes, which may align readers with protagonists and evoke empathy (Burke, 2010). (In this context it is interesting to note that, although Japanese does not allow reporting of others' internal states, in novels Japanese authors write as if they had privileged access to protagonist's mental states and report them directly.) All of this suggests tight links between emotion systems and language processing systems (Sanford \& Emmott, in press).

Emotions can be inferred from discourse, even when they are not explicitly mentioned. For example, Gernsbacher, Goldsmith, and Robertson (1992, p. 96) gave readers stories, such as:

\footnotetext{
Paul had always wanted his brother, Luke, to be good in baseball. So Paul had been coaching Luke after school for almost two years. In the beginning, Luke's skills were very rough. But after hours and hours of coaching, Paul could see great improvement. In fact, the improvement had been so great that at the end of the season, at the Little League Awards Banquet, Luke's name was called out to receive the Most Valuable Player Award.
}

Participants then read a sentence describing an emotional state congruent with that implied in the preceding passage (e.g., "It would be weeks before Paul's pride would subside") or one that was incongruent (e.g., "It would be weeks before Paul's guilt would subside"). Readers were faster reading the sentence with the congruent emotional state, suggesting they had inferred it during reading. Recent studies question whether readers really do make inferences of specific emotions, such as pride and guilt 
(Gygax, Garnham, \& Oakhill, 2004; Gygax, Oakhill, \& Garnham, 2003; although see Sanford \& Emmott, in press).

Comprehension of discourse is facilitated whilst in a congruent emotional state and inhibited whilst in an incongruent state. In one study, participants were asked to read sentences while holding a pen in their mouth (à la Strack, Martin, \& Stepper, 1988). Participants either held the pen with their teeth only, thus mimicking the expression of a smile, or with their lips only, which blocks a smiling expression. When sentences evoked valence congruent with the mimicked facial expression, processing time was faster than when wearing an incongruent facial expression (Havas, Glenberg, \& Rinck, 2007). In a separate study, participants who had botulinum toxin-A (botox) injected in the muscles responsible for frowning, thus temporarily paralyzing them, showed increased reading times for negative sentences (Havas, Glenberg, Gutowski, Lucarelli, \& Davidson, 2010). These studies support a "simulation" or "embodied" account of language, whereby the same neural systems responsible for perception and action are invoked during language processing.

Of interest here is the proposal by Havas and colleagues that emotion simulation, unlike action simulation, doesn't happen at the lexical level, but requires more linguistic material to occur. This seems at odds with other findings, suggesting immediate recruitment of emotion systems in language processing. Psycholinguistic studies show that people process language incrementally; they do not wait until the end of a sentence to process grammar and meaning, but build structures as language unfolds. According to a recent study, the affective component of words - as reflected in one's value system, for exampleinfluences the earliest aspects of language processing, modulating how deeply meaning is processed (Van Berkum, Holleman, Nieuwland, Otten, \& Murre, 2009). Members of a conservative Christian group, as well as non-Christians, were given sentences to read that were either congruent or incongruent with their moral value system, for example, I think euthanasia is an acceptable course of action. Van Berkum et al. (2009) found that, as soon as participants read a word that clashed with their beliefs (for the conservative Christian group the word acceptable in the example sentence), a neural signal, as measured by electroencephalography (EEG), indicated processing difficulty for the meaning of the word within that context and, moreover, additional resources were recruited to process the word subsequently. This suggests that even the earliest stages of language comprehension are sensitive to the emotional message of an utterance, especially when it is ego-threatening for the addressee.

In summary, it is likely that there are different processing streams for discourse about third parties, as depicted in narratives and literature, and discourse pertinent to one's own values and beliefs. Future research will need to clarify the exact time-course of integration of information from descriptive emotional words versus affect-laden words into discourse. In addition, the specificity of emotional inferences when understanding motives and goals of characters needs to be further clarified. Finally, all these processes need to be understood in the context of the possible goals of the comprehender.

\section{Conversation}

Stories are encountered not only when reading, but also during conversation. There are some particularly interesting things to learn about emotion by studying them in the context of everyday conversation. For example, when a speaker is retelling an earlier episode that involved emotion, the reconstructed affect will differ in systematic ways from that which was experienced. More importantly, conversation provides the exact testing ground for evaluating claims about how emotion functions in everyday behavior, claims such as: "Many believe that characteristic expressions of basic emotions 'erupt' in speech, often involuntarily, as one of the neurophysiological consequences of experiencing the emotion by the 'sender' or encoder of the expression" (Pell, Paulmann, Dara, et al., 2009, p. 417).

Through studying everyday conversation as it occurs between friends, family, and colleagues, or in the context of service encounters between customers and service providers, conversation analysts have illustrated the elegant dance of emotional display and timing. In an analysis of surprise, for example, Wilkinson and Kitzinger (2006) show that surprise tokens are not spontaneous, impulsive eruptions, but rather that "they are little performances of viscerality" (p. 161). Recipients delay surprise tokens and will withhold them over some time until the relevant place in the conversation opens up for their "eruption," for instance, the ending of the speaker's turn. Moreover, recipients "blurt out" a surprise response multiple times to the same surprise source, without the response losing its feeling of involuntariness and spontaneity. Wilkinson and Kitzinger argue that two people together produce surprise: One presents something surprising by highlighting the contrast between what might be expected to be the case and what actually happened, and the recipient produces the surprise reaction, conveying that they have understood that something unusual happened. The timing and sequence of these together "perform" surprise (see also Wilce, 2009).

In a cross-linguistic comparison, Couper-Kuhlen (2011) examined emotion in the context of requests. Asking something of someone can be perceived as a burden and the rejection of a request can be fraught. Couper-Kuhlen shows that both German and English requests follow parallel conversational trajectories, with similar types of emotion displays: disappointment and annoyance. According to her analysis, disappointment is part of the sadness family and is inward directed, whereas annoyance is part of the anger family and is associated with aggression and striking out. So, by displaying annoyance when a request is rejected, a speaker is implying that the rejecting party is at fault somehow, whereas by displaying disappointment, the speaker implies that the rejecting party can't help it. Moreover, because displays of annoyance are not "pro-social," they are dispreferred (see also Selting, 2010; Wiggins, 2002).

In summary, conversational data are a critical source of evidence for claims about emotion in its natural, ecological setting. The data presented earlier draw attention to the public aspects of emotion and language and suggest that 
emotional displays are not just direct outpourings from private physiology.

\section{Conclusion}

This brief review demonstrates that emotion is, indeed, relevant to every dimension of language - from phonology to lexicon, grammar and discourse-emotional expression is finely tuned to language-specific structures.

Based on current emotion research in the language sciences, one could ask whether there are generalizations to be made about what types of emotional meaning appear where. Is it the case, for example, that phonology only conveys information about affect, while lexicon conveys discrete emotion and grammar expresses attitude? This partitioning is too simplistic. Hearers appear to decode discrete emotions from prosody; words carry connotative meaning as well as descriptive meanings, and attitude can be conveyed by units smaller than the sentence. Nevertheless, it may be that certain linguistic structures are more suited to conveying particular aspects of emotion. Future emotion research ought to continue to exploit cross-linguistic variation to explore this issue, and to unravel additional principles operating between language and emotion.

\section{References}

Alonso-Arbiol, I., Shaver, P., Fraley, R. C., Oronoz, B., Unzurrunzaga, E., \& Urizar, R. (2006). Structure of the Basque emotion lexicon. Cognition \& Emotion, 20, 836-865.

Ameka, F. (1992). Interjections: The universal yet neglected part of speech. Journal of Pragmatics, 18, 101-118.

Anolli, L., Wang, L., Mantovani, F., \& De Toni, A. (2008). The voice of emotion in Chinese and Italian young adults. Journal of Cross-Cultural Psychology, 39, 565-598.

Arnett, J. J. (2008). The neglected 95\%: Why American psychology needs to become less American. American Psychologist, 63, 602-614.

Auracher, J., Albers, S., Zhai, Y., Gareeva, G., \& Stavniychuk, T. (2010). $\mathrm{P}$ is for happiness, $\mathrm{N}$ is for sadness: Universals in sound iconicity to detect emotions in poetry. Discourse Processes, 48, 1-25.

Barrett, L. F., \& Bliss-Moreau, E. (2009). Affect as a psychological primitive. In M. P. Zanna (Ed.), Advances in experimental social psychology (Vol. 41, pp. 167-218). Burlington, MA: Academic Press.

Barth-Weingarten, D., Reber, E., \& Selting, M. (Eds.). (2010). Prosody in interaction. Amsterdam, The Netherlands: John Benjamins Publishing Company.

Bergen, B. K. (2004). The psychological reality of phonaesthemes. Language, 80, 290-311.

Besnier, N. (1990). Language and affect. Annual Review of Anthropology, 19, 419-451.

Boster, J. S. (2005). Emotion categories across languages. In H. Cohen \& C. Lefebvre (Eds.), Handbook of categorization in cognitive science (pp. 187-222). Oxford, UK: Elsevier.

Breugelmans, S. M., \& Poortinga, Y. H. (2006). Emotion without a word: Shame and guilt among Rarámuri Indians and rural Javanese. Journal of Personality and Social Psychology, 91, 1111-1122.

Brown, R., \& Fish, D. (1983). Are there universal schemas of psychological causality? Archives de Psychologie, 51, 145-153.

Burke, M. (2010). Literary reading, cognition and emotion: An exploration of the oceanic mind. London, UK: Routledge.

Chomsky, N. (1980). Rules and representations. Oxford, UK: Blackwell.
Christiansen, M. H., \& Chater, N. (2008). Language as shaped by the brain. Behavioral and Brain Sciences, 31, 489-509.

Christiansen, M. H., \& Kirby, S. (Eds.). (2003). Language evolution. Oxford, UK: Oxford University Press.

Comrie, B. (1981). Language universals and linguistic typology. Chicago, IL: University of Chicago Press.

Couper-Kuhlen, E. (2011). Affectivity in cross-linguistic and cross-cultural perspective. In T. Stehl (Ed.), Sprachen in mobilisierten Kulturen: Aspekte der Migrationslinguistik [Languages in mobilizing cultures: Linguistic aspects of migration] (pp. 231-257). Berlin, Germany: Universitätsverlag Potsdam.

Cruse, D. A. (1986). Lexical semantics. Cambridge, UK: Cambridge University Press.

Cutler, A., Dahan, D., \& Van Donselaar, W. (1997). Prosody in the comprehension of spoken language: A literature review. Language and speech, 40, 141-201.

Darwin, C. (1871). The descent of man. London, UK: John Murray.

Delancey, S. (1997). Mirativity: The grammatical marking of unexpected information. Linguistic Typology, 1, 33-52.

Diffloth, G. (1972). Notes on expressive meaning. Chicago Linguistic Society, 8, 440-447.

Dingemanse, M. (2011). The meaning and use of ideophones in Siwu. (Unpublished Ph.D. thesis). Radboud University, The Netherlands.

Dixon, R. M. W. (2006). Adjective classes in typological perspective. In R. M. W. Dixon \& A. Y. Aikhenvald (Eds.), Adjective classes: A crosslinguistic typology (pp. 1-49). Oxford, UK: Oxford University Press.

Dixon, R. M. W., \& Aikhenvald, A. Y. (Eds.). (2006). Adjective classes: A cross-linguistic typology. Oxford, UK: Oxford University Press.

Dolscheid, S., Shayan, S., Majid, A., \& Casasanto, D. (2011). The thickness of musical pitch: Psychophysical evidence for the Whorfian hypothesis. In L. Carlson, C. Hölscher \& T. Shipley (Eds.), Proceedings of the 33rd Annual Conference of the Cognitive Science Society (pp. 537-542). Austin, TX: Cognitive Science Society.

Dunn, M., Greenhill, S. J., Levinson, S. C., \& Gray, R. D. (2011). Evolved structure of language shows lineage-specific trends in word-order universals. Nature, 473, 79-82.

Eitan, Z., \& Timmers, R. (2010). Beethoven's last piano sonata and those who follow crocodiles: Cross-domain mappings of auditory pitch in a musical context. Cognition, 114, 405-422.

Enfield, N. J., \& Wierzbicka, A. (Eds.). (2002). The body in description of emotion [Special issue]. Pragmatics \& Cognition, 10, 1-24.

Evans, N., \& Levinson, S. C. (2009). The myth of language universals: Language diversity and its importance for cognitive science. Behavioral and Brain Sciences, 32, 429-448.

Fetterman, A. K., Robinson, M. D., Gordon, R. D., \& Elliot, A. J. (2011). Anger as seeing red. Social Psychological and Personality Science, 2, $311-316$

Fodor, J. A. (1983). The modularity of mind. Cambridge, MA: MIT Press.

Fónagy, I. (1961). Communication in poetry. Word, 17, 194-218.

Foroni, F., \& Semin, G. R. (2009). Language that puts you in touch with your bodily feelings. Psychological Science, 20, $974-980$.

Friend, M. (2000). Developmental changes in sensitivity to vocal paralanguage. Developmental Science, 3, 148-162.

Geeraerts, D. (2006). Words and other wonders: Papers on lexical and semantic topics. Berlin, Germany: Walter de Gruyter.

Gernsbacher, M. A., Goldsmith, H. H., \& Robertson, R. R. W. (1992). Do readers mentally represent characters' emotional states? Cognition \& Emotion, 6, 89-111.

Gobl, C., \& Ní Chasaide, A. (2003). The role of voice quality in communicating emotion, mood and attitude. Speech Communication, 40, 189-212.

Goffman, E. (1981). Forms of talk. Philadelphia, PA: University of Pennsylvania Press.

Goodwin, M. H., \& Goodwin, C. (2001). Emotion within situated activity. In A. Duranti (Ed.), Linguistic anthropology: A reader (pp. 239-257). Malden, MA: Blackwell Publishing. 
Gygax, P., Garnham, A., \& Oakhill, J. (2004). Inferring characters' emotional states: Can readers infer specific emotions? Language and Cognitive Processes, 19, 613-639.

Gygax, P., Oakhill, J., \& Garnham, A. (2003). The representation of characters' emotional responses: Do readers infer specific emotions? Cognition \& Emotion, 17, 413-428.

Hagoort, P., \& Van Berkum, J. (2007). Beyond the sentence given. Philosophical Transactions of the Royal Society B: Biological Sciences, $362,801-811$.

Harkins, J., \& Wierzbicka, A. (Eds.). (2001). Emotions in crosslinguistic perspective. Berlin, Germany: Walter de Gruyter.

Hasegawa, Y., \& Hirose, Y. (2005). What the Japanese language tells us about the alleged Japanese relational self. Australian Journal of Linguistics, 25, 219-251.

Haspelmath, M. (2001). Non-canonical marking of core arguments in European languages. In A. Y. Aikhenvald, R. M. W. Dixon \& M. Onishi (Eds.), Non-canonical marking of subjects and objects (pp. 53-83). Amsterdam, The Netherlands: John Benjamins.

Havas, D. A., Glenberg, A. M., Gutowski, K. A., Lucarelli, M. J., \& Davidson, R. J. (2010). Cosmetic use of botulinum toxin-A affects processing of emotional language. Psychological Science, 21, 895-900.

Havas, D. A., Glenberg, A. M., \& Rinck, M. (2007). Emotion simulation during language comprehension. Psychonomic Bulletin \& Review, 14, 436-441.

Henrich, J., Heine, S. J., \& Norenzayan, A. (2010). The weirdest people in the world. Behavioral and Brain Sciences, 33, 1-75.

Hietanen, J. K., Leppänen, J. M., \& Lehtonen, U. (2004). Perception of emotions in the hand movement quality of Finnish sign language. Journal of Nonverbal Behavior, 28, 53-64.

Hockett, C. F. (1960). The origin of speech. Scientific American, 203, 89-96.

Huang, S. (2002). Tsou is different: A cognitive perspective on language, emotion, and body. Cognitive Linguistics, 13, 167-186.

Imai, M., Kita, S., Nagumo, M., \& Okada, H. (2008). Sound symbolism facilitates early verb learning. Cognition, 109, 54-65.

Iwasaki, N., Vinson, D. P., \& Vigliocco, G. (2007a). What do English speakers know about gera-gera and yota-yota? A cross-linguistic investigation of mimetic words for laughing and walking. Japanese Language Education Around the Globe, 17, 53-78.

Iwasaki, N., Vinson, D., \& Vigliocco, G. (2007b). How does it hurt, "kirikiri" or "siku-siku"? Japanese mimetic words of pain perceived by Japanese speakers and English speakers. In M. Minami (Ed.), Applying theory and research to learning Japanese as a foreign language (pp. 2-19). Newcastle, UK: Cambridge Scholars Publishing.

Jakobson, R. (1960). Linguistics and poetics. In T. Sebeok (Ed.), Style in language (pp. 350-377). Cambridge, MA: MIT Press

Jespersen, O. (1922). Language: Its nature, development and origin. London, UK: G. Allen \& Unwin.

King, K., \& Melzi, G. (2004). Intimacy, imitation and language learning: Spanish diminutives in mother-child conversation. First Language, 24, 241-261.

Klaiman, M. H. (1980). Bengali dative subjects. Lingua, 51, 275-295.

Kockelman, P. (2003). The meanings of interjections in Q'eqchi' Maya: From emotive reaction to social and discursive action. Current Anthropology, 44, 467-490.

Kövecses, Z. (2003). Metaphor and emotion: Language, culture, and body in human feeling. Cambridge, UK: Cambridge University Press.

Kulick, D., \& Schieffelin, B. B. (2004). Language socialization. In A. Duranti (Ed.), A companion to linguistic anthropology (pp. 347 368). Malden, MA: Blackwell.

Lakoff, G. (1987). Women, fire, and dangerous things: What categories reveal about the mind. Chicago, IL: University of Chicago Press.

Landau, I. (2009). The locative syntax of experiencers (Vol. 53). Cambridge, MA: MIT Press.
Langacker, R. W. (1987). Foundations of cognitive grammar: Theoretical prerequisites. Stanford, CA: Stanford University Press.

le Guen, O. (2009). The ethnography of emotions: A field worker's guide. In A. Majid (Ed.), Field manual (Vol. 12, pp. 31-34). Nijmegen, The Netherlands: Max Planck Institute for Psycholinguistics. Retrieved from http://fieldmanuals.mpi.nl/volumes/2009/ethnography-of-emotions/

Levinson, S. C. (2006). Parts of the body in Yélī Dnye, the Papuan language of Rossel Island. Language Sciences, 28, 221-240.

Lindholm, J. (1975). The conceptual basis of the Tamil adverbial participle. (Unpublished Ph.D. thesis). University of Chicago, USA.

Lupyan, G., \& Dale, R. (2010). Language structure is partly determined by social structure. PLOS ONE, 5, e8559.

Lyons, J. (1977). Semantics (Vol. 1). Cambridge, UK: Cambridge University Press.

Maddieson, I. (2011a). Consonant inventories. In M. S. Dryer \& M. Haspelmath (Eds.), The world atlas of language structures online. Munich, Germany: Max Planck Digital Library. Retrieved from http:// wals.info/chapter/1

Maddieson, I. (2011b). Vowel quality inventories. In M. S. Dryer \& M. Haspelmath (Eds.), The world atlas of language structures online. Munich, Germany: Max Planck Digital Library. Retrieved from http:// wals.info/chapter/1

Majid, A., Sanford, A. J., \& Pickering, M. J. (2007). The linguistic description of minimal social scenarios affects the extent of causal inference making. Journal of Experimental Social Psychology, 43, 918-932.

Masson, D. I. (1953). Vowel and consonant patterns in poetry. The Journal of Aesthetics and Art Criticism, 12, 213-227.

McGuire, W. J. (1969). The nature of attitudes and attitude change. The Handbook of Social Psychology, 3, 136-314.

McIntosh, D. N., Zajonc, R. B., Vig, P. S., \& Emerick, S. W. (1997). Facial movement, breathing, temperature, and affect: Implications of the vascular theory of emotional efference. Cognition \& Emotion, 11, 171-196.

Miall, D. S. (2001). Sounds of contrast: An empirical approach to phonemic iconicity. Poetics, 29, 55-70.

Moore, C. C., Romney, A. K., Hsia, T., \& Rusch, C. D. (1999). The universality of the semantic structure of emotion terms: Methods for the study of inter- and intra-cultural variability. American Anthropologist, $101,529-546$.

Nuckolls, J. B. (1999). The case for sound symbolism. Annual Review of Anthropology, 28, 225-252.

Oatley, K. (1992). Best laid schemes: The psychology of emotions. Cambridge, UK: Cambridge University Press.

Oda, H. (2000). An embodied semantic mechanism for mimetic words in Japanese. (Unpublished Ph.D. thesis). Indiana University, Bloomington, USA.

Ogarkova, A. (in press). Folk emotion concepts: Lexicalization of emotional experiences across languages and cultures. In J. Fontaine, K. R. Scherer \& S. Soriano (Eds.), Components of emotional meaning: A sourcebook. Oxford, UK: Oxford University Press.

Onishi, M. (2001). Non-canonically marked subjects and objects: Parameters and properties. In A. Y. Aikhenvald, R. M. W. Dixon \& M. Onishi (Eds.), Non-canonical marking of subjects and objects (pp. 1-111). Amsterdam, The Netherlands: John Benjamins.

Osaka, N., \& Osaka, M. (2005). Striatal reward areas activated by implicit laughter induced by mimic words in humans: A functional magnetic resonance imaging study. NeuroReport, 16, 1621.

Pell, M. D., Monetta, L., Paulmann, S., \& Kotz, S. A. (2009). Recognizing emotions in a foreign language. Journal of Nonverbal Behavior, 33, $107-120$

Pell, M. D., Paulmann, S., Dara, C., Alasseri, A., \& Kotz, S. A. (2009). Factors in the recognition of vocally expressed emotions: A comparison of four languages. Journal of Phonetics, 37, 417-435.

Pinker, S. (1994). The language instinct. New York, NY: Morrow \& Co. 
Pinker, S. (2007). The stuff of thought: Language as a window into human nature. London, UK: Alan Lane.

Potts, C., Asudeh, A., Cable, S., Hara, Y., McCready, E., Alonso-Ovalle, L., ... Walkow, M. (2009). Expressives and identity conditions. Linguistic Inquiry, 40, 356-366.

Pullum, G. K., \& Rawlins, K. (2007). Argument or no argument? Linguistics and Philosophy, 30, 277-287.

Quam, C., \& Swingley, D. (2012). Development in children's interpretation of pitch cues to emotions. Child Development, 83, 246-250.

Reilly, J. S., Mcintire, M. L., \& Seago, H. (1992). Affective prosody in American sign language. Sign Language Studies, 75, 113-128.

Roberson, D., Damjanovic, L., \& Kikutani, M. (2010). Show and tell: The role of language in categorizing facial expression of emotion. Emotion Review, 2, 255-260.

Robinson, S. (2006). The phoneme inventory of the Aita dialect of Rotokas. Oceanic Linguistics, 45, 206-209.

Russell, J. A. (1980). A circumplex model of affect. Journal of Personality and Social Psychology, 39, 1161-1178.

Russell, J. A., Bachorowski, J. A., \& Fernández-Dols, J. M. (2003). Facial and vocal expressions of emotion. Annual Review of Psychology, 54, 329-349.

Sanford, A. J., \& Emmott, C. (in press). Mind, brain and narrative. Cambridge, UK: Cambridge University Press.

Sauter, D. A., Eisner, F., Ekman, P., \& Scott, S. K. (2010). Cross-cultural recognition of basic emotions through nonverbal emotional vocalizations. Proceedings of the National Academy of Sciences, 107, 2408.

Sauter, D. A., LeGuen, O., \& Haun, D. B. M. (2011). Categorical perception of emotional facial expressions does not require lexical categories. Emotion, 11, 1479-1483.

Scherer, K. R., Banse, R., \& Wallbott, H. G. (2001). Emotion inferences from vocal expression correlate across languages and cultures. Journal of Cross-Cultural Psychology, 32, 76-92.

Scherer, K. R., Clark-Polner, E., \& Mortillaro, M. (2011). In the eye of the beholder? Universality and cultural specificity in the expression and perception of emotion. International Journal of Psychology, 46, 401-435.

Selting, M. (2010). Affectivity in conversational storytelling: An analysis of displays of anger or indignation in complaint stories. Pragmatics, 20, 229-277.

Semin, G. R., \& Fiedler, K. (1988). The cognitive functions of linguistic categories in describing persons: Social cognition and language. Journal of Personality, 54, 558-568.

Sereno, J. A. (1994). Phonosyntactics. In L. Hinton, J. Nichols \& J. J. Ohala (Eds.), Sound symbolism (pp. 263-275). Cambridge, UK: Cambridge University Press.

Shayan, S., Ozturk, O., \& Sicoli, M. A. (2011). The thickness of pitch: Crossmodal metaphors in Farsi, Turkish, and Zapotec. The Senses and Society, 6, 96-105.

Shibatani, M. (1990). The languages of Japan. Cambridge, UK: Cambridge University Press.

Sicoli, M. A. (2010). Shifting voices with participant roles: Voice qualities and speech registers in Mesoamerica. Language in Society, 39, 521-553.

Silverstein, M. (2001). The limits of awareness. In A. Duranti (Ed.), Linguistic anthropology: A reader (pp. 382-401). Malden, MA: Blackwell Publishing.

Strack, F., Martin, L. L., \& Stepper, S. (1988). Inhibiting and facilitating conditions of the human smile: A nonobtrusive test of the facial feedback hypothesis. Journal of Personality and Social Psychology, $54,768-777$.

Taylor, I. K., \& Taylor, M. M. (1965). Another look at phonetic symbolism. Psychological Bulletin, 64, 413-427.

Thompson, W. F., \& Balkwill, L.-L. (2006). Decoding speech prosody in five languages. Semiotica, 158, 407-424.
Toivonen, R., Kivelä, M., Saramäki, J., Viinikainen, M., Vanhatalo, M., \& Sams, M. (2012). Networks of emotion concepts. PLoS ONE, 7, e28883.

Trechter, S. (1999). Contextualizing the exotic few: Gender dichotomies in Lakhota. In M. Bucholtz, A. C. Liang \& L. A. Sutton (Eds.), Reinventing identities: The gendered self in discourse (pp. 101-119). Oxford, UK: Oxford University Press.

Trudgill, P. (2011). Sociolinguistic typology: Social determinants of linguistic complexity. Oxford, UK: Oxford University Press.

Tsur, R. (1992). What makes sound patterns expressive? The poetic mode of speech perception. Durham, NC: Duke University Press.

Van Berkum, J. J. A., Holleman, B., Nieuwland, M., Otten, M., \& Murre, J. (2009). Right or wrong? The brain's fast response to morally objectionable statements. Psychological Science, 20, 1092-1099.

Verhoeven, E. (2007). Experiential constructions in Yucatec Maya: A typologically based analysis of a functional domain in a Mayan language. Amsterdam, The Netherlands: John Benjamins.

Von Essen, O. (1979). Allgemeine und angewandte Phonetik: mit 9 Tabellen [General and applied phonetics: With 9 tables]. Berlin, Germany: DDR.

Wharton, T. (2003). Interjections, language, and the showing/saying continuum. Pragmatics \& Cognition, 11, 39-91.

Whissell, C. (1989). The dictionary of affect in language. In R. Plutchik \& H. Kellerman (Ed.), Emotion: Theory, research, and experience (pp. 113-131). New York, NY: Academic Press.

Whissell, C. (1999). Phonosymbolism and the emotional nature of sounds: Evidence of the preferential use of particular phonemes in texts of differing emotional tone. Perceptual and Motor Skills, 89, 19-48.

Whissell, C. (2003). The emotional symbolism of two English e-sounds: /I/ as in "cheap" is pleasant and /I/ as in "chip" active. Perceptual and Motor Skills, 96, 149-165.

Wierzbicka, A. (1988). The semantics of grammar. Amsterdam, The Netherlands: John Benjamins.

Wierzbicka, A. (1992). The semantics of interjection. Journal of Pragmatics, 18, 159-192.

Wierzbicka, A. (1996). Semantics: Primes and universals. Oxford, UK: Oxford University Press.

Wierzbicka, A. (1999). Emotions across languages and cultures: Diversity and universals. Cambridge, UK: Cambridge University Press.

Wierzbicka, A. (2009). Language and metalanguage: Key issues in emotion research. Emotion Review, 1, 3-14.

Wiggins, S. (2002). Talking with your mouth full: Gustatory mmms and the embodiment of pleasure. Research on Language and Social Interaction, $35,311-336$

Wilce, J. M. (2009). Language and emotion. Cambridge, UK: Cambridge University Press.

Wilkins, D. P. (1992). Interjections as deictics. Journal of Pragmatics, 18, $119-158$.

Wilkinson, S., \& Kitzinger, C. (2006). Surprise as an interactional achievement: Reaction tokens in conversation. Social Psychology Quarterly, 69, 150-182.

Wilkowski, B. M., Meier, B. P., Robinson, M. D., Carter, M. S., \& Feltman, R. (2009). "Hot-headed" is more than an expression: The embodied representation of anger in terms of heat. Emotion, 9, 464-477.

Yu, N. (2003). Metaphor, body, and culture: The Chinese understanding of gallbladder and courage. Metaphor and Symbol, 18, 13-31.

Zajonc, R. B., Murphy, S. T., \& Inglehart, M. (1989). Feeling and facial efference: Implications of the vascular theory of emotion. Psychological Review, 96, 395-416.

Zwicky, A. M., Salus, P., Binnick, R. I., \& Vanek, A. (Eds.) (1971). Studies out in left field: Defamatory essays presented to James D. McCawley on the occasion of his 33rd or 34th birthday. Edmonton, Canada: Linguistic Research. 